\title{
Pengukuran Metrik Kompleksitas Web Service Sekolah
}

\author{
Ahmad Riza ${ }^{1}$, Mohamad Alif Irfan Anshori ${ }^{2}$, Farrah Arrazy ${ }^{3}$ \\ 1),2),3) Teknik Informatika, Universitas Islam Negeri (UIN) Maulana Malik Ibrahim Malang \\ Jl. Gajayana No. 50 Malang 65144 - Indonesia \\ Email: riza.public@gmail.com ${ }^{1)}$, alif.anshory16@gmail.com²), farraharrazyrazy@gmail.com ${ }^{3)}$
}

\begin{abstract}
The Complexity Metric Diagram is a method of measuring software complexity. This method uses Class Diagrams as test parameters. This study uses test data from previous research regarding the design of Information Systems accompanied by Class Diagrams with case studies of School Academic Information Systems. The facts found in the field that school software developers do not conduct application audits so it is not ripe to face problems that will arise in the future. The results of the calculation of the complexity metrics in the School Academic Information System produce an output of 993.32 units.
\end{abstract}

Keywords: Complexity Metrics, Web Service, School Academic System

\begin{abstract}
Abstrak
Metriks Kompleksitas Diagram merupakan metode pengukuran tingkat kerumitan perangkat lunak. Metode ini mengunakan Class Diagram sebagai parameter ujinya. Penelitian ini menggunakan data uji dari penelitian sebelumnya mengenai perancangan Sistem Informasi yang disertai Class Diagram dengan studi kasus Sistem Informasi Akademik Sekolah. Fakta dilapangan ditemukan bahwa pengembang perangkat lunak sekolah kurang melakukan audit aplikasi sehingga tidak matang menghadapi masalah yang akan muncul di masa yang akan datang. Hasil dari perhitungan metriks kompleksitas pada Sistem Informasi Akademik Sekolah menghasilkan output sebesar 993,32 unit.
\end{abstract}

Kata Kunci: Metrik Kompleksitas, Web Service, Sistem Akademik Sekolah

\section{PENDAHULUAN}

Pada zaman yang dimana teknologinya telah berkembang dengan pesatnya, banyak teknologi yang seringkali membantu kehidupan masyarakat sehari-hari, seperti Internet of Things (IoT) terutama software berbasis mobile, website, dan desktop. Perkembangan teknologi terutama dalam bidang sistem informasi saat ini sangat memungkinkan dalam pemanfaatan penyebaran informasi. Dalam hal ini, dapat dimanfaatkan di bidang pendidikan. Sebelumnya, menurut UU No 20 Tahun 2003, pendidikan adalah usaha sadar dan terencana untuk mewujudkan suasana belajar dan proses pembelajaran agar peserta didik secara aktif mengembangkan potensi dirinya untuk memiliki kekuatan spiritual keagamaan, pengendalian diri, kepribadian, kecerdasan, akhlak mulia, serta keterampilan yang diperlukan dirinya, masyarakat, bangsa, dan negara. Terkait hal itu, sistem informasi dapat membantu kegiatan akademik, seperti penerimaan mahasiswa baru, pembuatan kurikulum, pembuatan jadwal mata pelajaran, serta pengelolaan data guru dan siswa. Penelitian ini akan melakukan pengukuran kompleksitas terhadap web service sekolah dengan menggunakan metode complexity class diagram. 


\section{METODOLOGI PENELITIAN}

\subsection{Dasar Teori}

\subsubsection{Web Service}

Web service adalah generasi baru dari aplikasi Web. Mereka mandiri, menggambarkan diri sendiri, aplikasi modular yang dapat dipublikasikan, ditemukan, dan dipanggil di seluruh Web. Web service menjalankan fungsi, yang bisa berupa apa saja dari permintaan sederhana hingga proses bisnis yang rumit. Setelah layanan Web digunakan, aplikasi lain (dan layanan Web lainnya) dapat menemukan dan menjalankan layanan yang digunakan.

Web service juga merupakan sebuah layanan yang diperuntukkan agar sebuah platform dapat berkomunikasi dengan platform yang lain. Sehingga sebuah sistem yang menggunakan web service dapat mendukung fitur multi-platform. Bentuk umum umum dari web service adalah WSDL (Web Service Description Language) dan REST (Representational State Transfer). WSDL menggunakan komunikasi SOAP (Simple Object Access Protocol) sedangkan REST menggunakan komunikasi dengan PUT, GET, POST dan memiliki return seperti HTML, XML, JSON, atau struktur yang ditentukan sendiri.

\subsubsection{Class Diagram}

Class diagram adalah deskripsi yang paling penting dan paling banyak digunakan dari sebuah sistem berbasis objek. Class diagram menunjukkan struktur statis dari class-class inti yang membangun sistem. Class diagram menampilkan attribute dan method pada setiap class. Class diagram juga menampilkan relation yang terdapat di antara setiap class.

Dalam class diagram, kelas-kelas tersebut diatur dalam kelompok-kelompok yang memiliki karakteristik yang sama. Class diagram menyerupai diagram alur di mana class digambarkan sebagai kotak, masing-masing kotak memiliki tiga persegi panjang di dalamnya. Kotak atas berisi nama class; kotak tengah berisi atribut class; persegi panjang yang lebih rendah berisi method, juga disebut operation, class. Garis, yang mungkin memiliki panah di salah satu atau kedua ujungnya, hubungkan kotak. Garis-garis ini mendefinisikan hubungan, juga disebut asosiasi, antara kelaskelas.

\subsubsection{Metrik Skala Kompleksitas Class Diagram}

Metrik skala kompleksitas class diagram merepresentasikan tingkat kerumitan class yang digambarkan dengan class diagram pada suatu program. Berdasarkan Object Oriented Programming (OOP) yang merupakan bahasa pemrograman yang telah dirancang di sekitar object daripada "prosedur" dan informasi aktual daripada pemrograman logika. Pada dasarnya, sebuah program adalah serangkaian method yang dapat dieksekusi yang mengambil data sebagai input, melakukan pemrosesan, dan kemudian memberikan hasil yang diinginkan. Upaya aktual atau fondasi pemrograman difokuskan pada cara menulis logika daripada definisi data. OOP yang terutama menekankan bahwa object dalam paradigma pemrograman adalah object yang harus diubah sesuai dengan kebutuhan dan penggunaan kita dan bukan logika yang diperlukan di balik manipulasinya. class terdiri dari method (Method), atribut (Attribute), dan relasi 
(Relation). Sehingga, metrik skala dan kompleksitas class diagram dapat diformulasikan sebagai berikut:

$$
\begin{aligned}
\text { Class }= & \left(0.637 \cdot \sum \text { Method }\right) \\
& +\left(0.258 \cdot \sum \text { Attribute }\right) \\
& +\left(0.105 \cdot \sum \text { Relation }\right)
\end{aligned}
$$

\subsubsection{Metrik Skala Kompleksitas Method}

Metrik skala kompleksitas method merepresentasikan tingkat kerumitan method pada suatu class. Kompleksitas method ditentukan skala kompleksitas alur program yang direpresentasikan menggunakan flowchart. Namun berdasarkan batasan masalah, perhitungan dilakukan dengan mengabaikan kompleksitas method, sehingga diasumsikan kompleksitas setiap method bernilai 1.

\subsubsection{Metrik Skala Kompleksitas Attribute}

Metrik skala kompleksitas attribute merepresentasikan tingkat kerumitan atribut-atribut pada suatu class. skala kompleksitas attribute ditentukan berdasarkan tipe data (DT) dan lebar datanya (DW). Setiap tipe data memiliki bobot tertentu berdasarkan tabel berikut.

Tabel 1. Skala Kompleksitas Attribute

\begin{tabular}{|l|c|}
\hline \multicolumn{1}{|c|}{ Tipe Data } & Bobot \\
\hline Bit & 0.01 \\
\hline Tinyint, year & 0.06 \\
\hline Smallint & 0.11 \\
\hline Char, binary, tinytext, tinyblob & 0.12 \\
\hline Text, blob, varchar, varbinary & 0.16 \\
\hline Mediumint, time & 0.17 \\
\hline Int, float, timestamp & 0.22 \\
\hline Mediumtext, mediumblob & 0.24 \\
\hline Bigint, double, decimal, real, numeric, datetime, time & 0.44 \\
\hline Longtext, longblob & 0.48 \\
\hline
\end{tabular}

Skala kompleksitas Attibut dapat diformulasikan sebagai berikut:

$$
\text { Attribute }=D T \cdot D W
$$

\subsubsection{Metrik Skala Kompleksitas Relation}

Metrik skala kompleksitas relation merepresentasikan tingkat kerumitan relasi antara class satu dengan yang lain pada suatu class diagram. Kompleksitas Relasi (Relation) dalam class diagram didapatkan dari penjumlahan berbagai tipe relasi yang ada dalam class diagram tersebut. Jenis-jenis relasi yang ada dalam class diagram adalah Inheritance (Inheritance), Association (Association), Composition (Composition), dan Aggregation (Aggregation). Skala kompleksitas relation dapat diformulasikan sebagai berikut:

$$
\begin{aligned}
& \text { Relation }=(a \cdot \text { Inheritance })+(b \cdot \text { Association })+(c \cdot \text { Composition })+(d \cdot \\
& \text { Aggregation })
\end{aligned}
$$


Jurnal Riset Sistem Informasi Dan Teknik Informatika (JURASIK) Volume 5 Nomor 1 Februari, pp 147-153 ISSN: 2527-5771/EISSN: 2549-7839

http://tunasbangsa.ac.id/ejurnal/index.php/jurasik

\section{HASIL DAN PEMBAHASAN}

\subsection{Class Diagram}

Penelitian ini menggunakan 3 sistem kelas diagram, yakni: Akademik, Perpustakaan, dan Keuangan dengan menerapkan arsitektur Microservices dan berkomunikasi antara satu dengan yang lain dengan protokol REST. Dengan menggeneralisasi setiap tipe data memiliki bobot sebagai berikut:

String $=256$

Int $=171$

Enum $=100$

DateTime $=7$

\subsubsection{Akademik}

Class Diagram Akademik terdiri dari 6 kelas dengan total 31 attribute dan 34 method.

\begin{tabular}{|l|}
\hline \multicolumn{1}{|c|}{ Guru } \\
\hline id \\
nip \\
guru \\
id_pelajaran \\
id_status_guru \\
keterangan \\
\hline create_guru() \\
update_guru() \\
delete_guru() \\
list_guru() \\
cari_guru() \\
get_JSON() \\
\hline
\end{tabular}

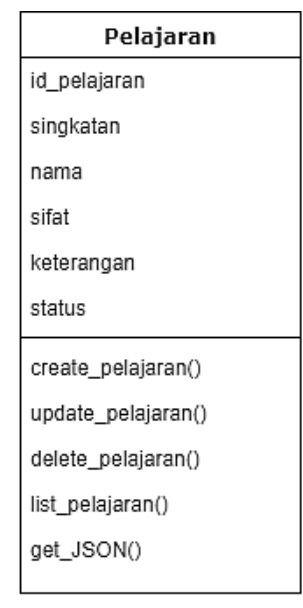

\begin{tabular}{|l|}
\hline \multicolumn{1}{|c|}{ Jam } \\
\hline id \\
waktu \\
\hline create_jam0 \\
update_jam0 \\
delete_jam() \\
list_jam() \\
get_JSONO \\
\hline
\end{tabular}
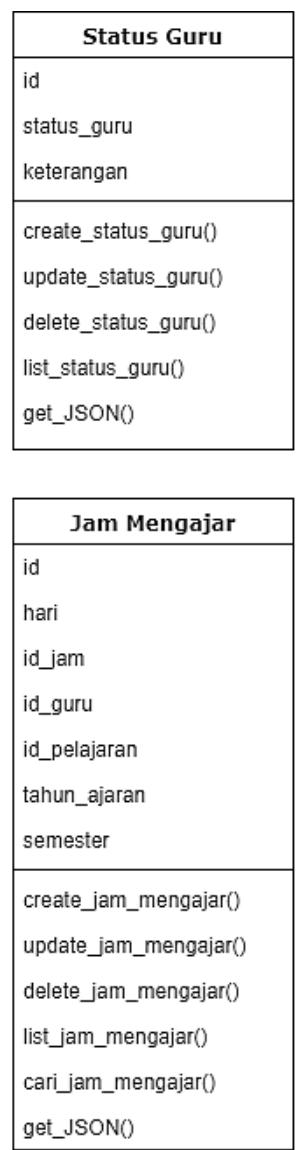

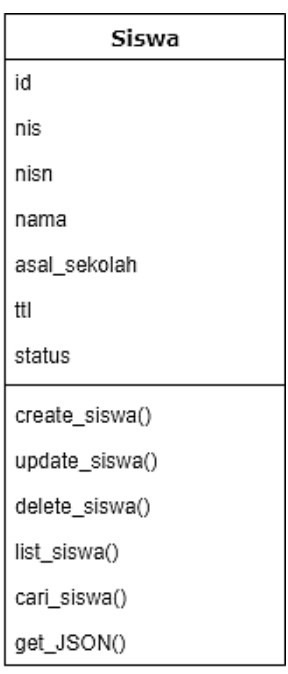

get_JSON()

Gambar 1. Class Diagram Akademik

\subsubsection{Perpustakaan}

Class Diagram Akademik terdiri dari 8 kelas dengan total 31 attribute dan 34 method. 
Jurnal Riset Sistem Informasi Dan Teknik Informatika (JURASIK) Volume 5 Nomor 1 Februari, pp 147-153 ISSN: 2527-5771/EISSN: 2549-7839

http://tunasbangsa.ac.id/ejurnal/index.php/jurasik

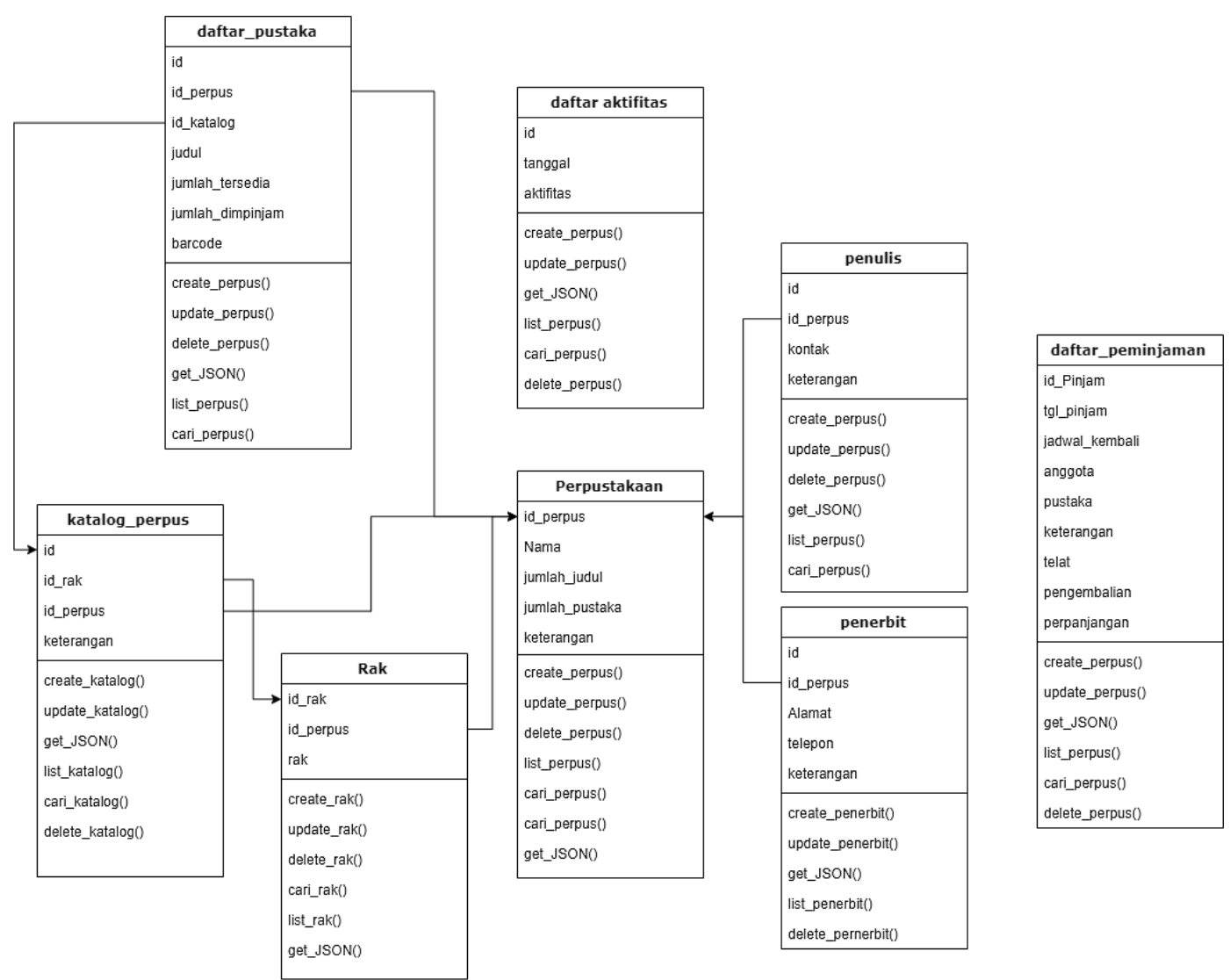

Gambar 2. Class Diagram Perpustakaan

\subsubsection{Keuangan}

Class Diagram Akademik terdiri dari 8 kelas dengan total 43 attribute dan 37 method. 
Jurnal Riset Sistem Informasi Dan Teknik Informatika (JURASIK) Volume 5 Nomor 1 Februari, pp 147-153 ISSN: 2527-5771/EISSN: 2549-7839 http://tunasbangsa.ac.id/ejurnal/index.php/jurasik

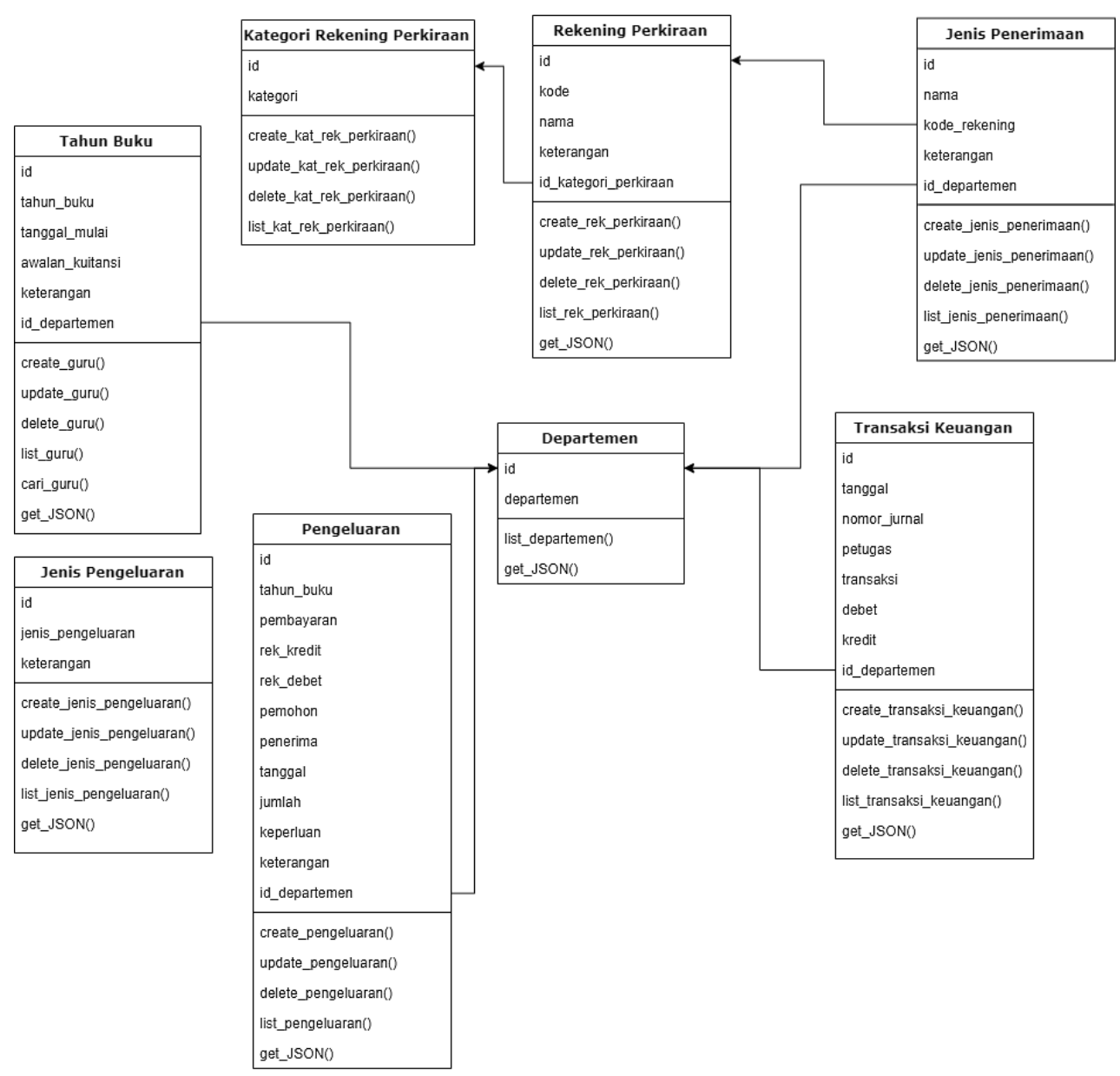

Gambar 3. Class Diagram Keuangan

\subsection{Skala Kompleksitas Attribute}

Berikut persamaan dari skala kompleksitas Attribute.
$\sum$ Attribute
$=D T \cdot D W$
Attribute Akademik $=1221.12$
Attribute Perpustakaan $=611.94$
Attribute Keuangan $=1509.42$
SAttribute $\quad=3342.49$

\subsection{Skala Kompleksitas Method}

Berikut persamaan dari skala kompleksitas Method.

SMethod $=($ Method Akademik $)$

$$
\begin{aligned}
& +(\text { Method Perpustakaan }) \\
& +(\text { Method Keuangan }) \\
& =118
\end{aligned}
$$

\subsection{Skala Kompleksitas Relation}

Berikut persamaan dari skala kompleksitas Relation.

SRelation $=($ Relation Akademik) 


$$
\begin{gathered}
+(\text { Relation Perpustakaan }) \\
+(\text { Relation Keuangan }) \\
=0+7 \text { Association } \\
\quad+6 \text { Association } \\
=13
\end{gathered}
$$

\section{5. kala Kompleksitas Class Diagram}

Berikut persamaan dari skala kompleksitas Class Diagram.

$$
\begin{aligned}
\text { Class }= & \left(0.258 \cdot \sum \text { Attribute }\right) \\
& +\left(0.637 \cdot \sum \text { Method }\right) \\
& +\left(0.105 \cdot \sum \text { Relation }\right) \\
& =862.36+75,17+1,37 \\
& =938,9
\end{aligned}
$$

\section{SIMPULAN}

Kompleksitas Class Diagram dapat dihitung dari penjumlahan kompleksitas method (Method), atribut (Attribute), dan relasi (Relation). Dari hasil perhitungan, diperoleh kesimpulan bahwa Class Diagram Sistem Informasi Akademik Sekolah diatas memiliki tingkat kompleksitas kode sebesar 993,32 unit.

\section{UCAPAN TERIMA KASIH}

Pertama-tama, penulis menghaturkan terima kasih kepada dosen pengampu mata kuliah Manajemen Proyek, Bapak Ainul Yaqin, M.Kom atas bimbingan dalam penulisan serta arahannya. Lalu, terima kasih kepada teman-teman Andromeda yang telah memberikan dukungan moral serta bantuan kepada penulis. Penulis sangat mengapresiasi serta rasa syukur akan bantuan dari teman-teman Andromeda.

\section{DAFTAR PUSTAKA}

[1] Fensel, D., \& Bussler, C. (2002). The Web Service Modeling Framework WSMF. Electronic Commerce Research and Applications, 1(2), 113-137. doi:10.1016/s1567-4223(02)00015-7

[2] Lanza, M., Marinescu, R., Ducasse, S. (2006). Object-Oriented Metrics in Practice: Using Software Metrics to Characterize, Evaluate, and Improve the Design of ObjectOriented Systems. Springer Science \& Business, Berlin.

[3] Skogan, D., Grønmo, R., Solheim, I. (2004). Web Service Composition in UML. IEEE International Enterprise Distributed Object Computing Conference, Oslo .

[4] Souri, A., Mohammad ali Sharifloo, \& Norouzi, M. (2011). Formalizing class diagram in UML. 2011 IEEE 2nd International Conference on Software Engineering and Service Science. doi:10.1109/icsess.2011.5982368

[5] Tan, R., \& Caroline, W. A., (2018). Pemrograman Web dengan PHP. Google Play Books.

[6] Tonella, P., \& Potrich, A. (2007). Reverse Engineering of Object Oriented Code. Springer Science \& Business, New York.

[7] Urdhwareshe, A. (2016). Object-Oriented Programming and its Concepts. Innovative Space of Scientific Research Journals, Bridgeport. 